\title{
RECRUITMENT MANAGEMENT OF EDUCATORS AT THE STATE ELEMENTARY SCHOOL OF SINDUADI 1 SLEMAN YOGYAKARTA
}

\author{
Heni Nurhayanti, Ismi Fadila \\ Universitas Sebelas Maret \\ heninurhayanti5@gmail.com
}

\section{Article History}

accepted 09/07/2018

approved 01/08/2018

published 17/09/2018

\section{Keywords}

recruitment management, educators, elementary school

\begin{abstract}
The quality of human resources is very influential on the achievement of school vision and mission. Determination of the quality of human resources in schools can be known from the recruitment management of educators. Therefore the purpose of this study is to know the recruitment management of educators in SDN Sinduadi 1. The research method used is qualitative descriptive. The results show that schools perform the required job analysis, determine recruitment strategies such as announcement of new teacher vacancies within the internal scope and use appropriate sources, techniques and recruitment methods. Implementation of recruitment, this school never made an announcement in the mass media only dilingkup internal to the teacher staff. Selection is done by the principal by way of file selection and then followed by interview. After that, the principal decides who the teacher will receive. The conclusion of this research is the management of recruitment of educator at SDN Sinduadi 1 is still less coordinated.
\end{abstract}

Social, Humanities, and Education Studies (SHEs): Conference Series https://jurnal.uns.ac.id/shes
p-ISSN 2620-9284

e-ISSN 2620-9292 


\section{PENDAHULUAN}

Salah satu faktor terpenting dalam meningkatkan mutu pendidikan adalah sumber daya manusia. Oleh karena itu, proses rekrutmen sumber daya manusia (SDM) menjadi hal yang sangat penting dan hanya akan dapat diperoleh melalui upaya rekrutmen yang efektif. Mengenai informasi yang akurat dan berkelanjutan tentang jumlah dan kualifikasi yang diperlukan untuk berbagai bidang pekerjaan dan untuk pengembangan dan pencapaian tujuan sebuah lembaga pendidikan. Tentu saja rekrutmen yang dilakukan haruslah sesuai dengan kebutuhan sekolah, dan persyaratan yang ditentukan oleh sekolah. Agar rekrutmen yang dilakukan tidak hanya sekedar mengisi kekosongan pegawai atau sekedar mendapatkan sumber daya manusia (SDM) yang biasa saja, tetapi sumber daya manusia (SDM) yang dapat berdedikasi dan profesional di bidangnya sehingga dapat meningkatkan mutu pendidikan sekolah tersebut.

Keberhasilan sekolah untuk mendapatkan sumber daya manusia yang berkualitas tidak lepas dari upaya pihak sekolah untuk mengadakan rekrutmen yang baik. Di mana dengan melalui proses rekrutmen ini dapat menghasilkan satu kelompok pelamar yang memenuhi syarat untuk bekerja di lembaga pendidikan tersebut. Semua kegiatan tersebut akhirnya akan terpulang kepada sejumlah orang (tenaga kependidikan) yang terlibat. Oleh karena itu peran mereka sangat menentukan gagal atau berhasilnya pelaksanaan tugas. Mereka itu haruslah dipersiapkan secara khusus, terpelajar dan terpilih.

Salah satu jalan keefektivitas sekolah dapat dibuat melalui tindakan administratif untuk meningkatkan kriteria dan prosedur pemilihan anggota staf guru sekolah. Prosedur seleksi yang gegabah, lebih-lebih jika pengangkatan personil dilakukan tanpa seleksi sama sekali dapat membawa kepada penumpukan personil yang tidak mampu atau tidak cocok, yang menghambat usaha perbaikan daya guna sekolah. Karena itu, suatu prosedur seleksi yang teliti adalah esensial dalam mengisi setiap kedudukan di sekolah. Salah satu sumbangan paling besar kepada efektivitas sekolah yang dapat dibuat oleh administrator sekolah ialah untuk menjamin bahwa prosedur dan kriteria seleksi membawa kepada penempatan personil yang bermutu dan cocok.

Satu bagian penting dari tanggung jawab kepala sekolah ialah untuk menciptakan prosedur yang logis dan memadai untuk menaksir kebutuhan program sekolah akan personil serta menetapkan kualifikasi profesional dan pribadi dari personil yang dibutuhkan itu. Kepala sekolah hendaknya atau berusaha untuk memperoleh wewenang untuk melakukan fungsi-fungsi ini atau ia menciptakan kerja sama yang erat dengan pejabat departemen pendidikan yang diberi tanggung jawab tentang administrasi personil sekolah. Maka dari itu, penulis ingin mengetahui bagaimana manajemen rekrutmen tenaga pendidik di SDN 1 Sinduadi sehingga dapat menghasilkan tenaga pendidik yang memiliki kualitas dan profesional sesuai dengan bidangnya.

Jones (2004: 4) Management is the planning, organizing, leading, and controlling of human and other resources to achieve organizational goals effectively and efficiently. Manajemen adalah perencanaan, pengorganisasian, memimpin, dan mengendalikan sumber daya manusia dan sumber-sumber lain untuk mencapai tujuan organisasi secara efektif dan efisien.

Pynes (2002:168), Recruitment is the process of attracting qualified candidates to apply for vacant positions within an organization. Berdasarkan pendapat Pynes dapat diketahui bahwa rekrutmen merupakan proses menarik kandidat yang memenuhi syarat untuk melamar posisi kosong dalam suatu organisasi

Menurut Gomes (2003: 105) mengatakan bahwa rekrutmen dilaksanakan dalam suatu organisasi karena kemungkinan adanya lowongan dengan beraneka ragam dasar atau alasan di antaranya adalah: berdirinya organisasi baru, adanya perluasan kegiatan organisasi; terciptanya pekerjaan-pekerjaan dan kegiatan-kegiatan baru; 
adanya pekerja yang pindah ke organisasi lain; adanya pekerja yang berhenti, baik dengan hormat maupun tidak hormat; adanya pekerja yang berhenti karena memasuki usia pensiun; dan adanya pekerja yang meninggal dunia.

Dalam praktiknya pelaksanaan rekrutmen memiliki beberapa tujuan yang ingin dicapai yaitu :

a. Memperoleh sumber tenaga yang potensial

b. Memperoleh sejumlah pelamar yang memenuhi kualifikasi

c. Menentukan kriteria minimal untuk calon pelamar

d. Untuk keutuhan seleksi. (Kasmir: 2012)

Suatu kegiatan manajemen yang baik tentu diawali dengan suatu perencanaan yang matang dan baik. Perencanaan rekrutmen dilakukan dengan analisis pekerjaan. Menurut Hasibuan (2012), analisis pekerjaan adalah menganalisis dan mendesain pekerjaan apa saja yang harus dikerjakan, bagaimana mengerjakannya, dan mengapa pekerjaan itu harus dikerjakan.

Proses pelaksanaan rekrutmen yang baik adala sebagai berikut: (1) Penentuan dasar rekrutmen; (2) Penentuan sumber-sumber rekrutmen; (3) Metode-metode rekrutmen; (4) Kenadala-kendala rekrutmen (Hasibuan: 2012).

Menurut Hasibuan (2008), Sumber penarikan calon karyawan bisa berasal dari internal dan eksternal perusahaan. Menurut Priansa (2004), metode calon karyawan baru, dibagi menjad metode terbuka dan metode tertutup. Teknik rekrutmen dapat dilakukan melalui asas sentralisasi dan asas desentralisai, tergantung pada keadaan organisasi, kebutuhan, dan jumlah calon pegawai yang hendak direkrut (Priansa: 2004).

Menurut Hasibuan (2008) agar proses perekrutan berhasil, maka perusahaan perlu menyadari berbagai kendala yang bersumber dari organisasi, pelaksana penarikan, dan lingkungan eksternal.

Menurut Undang-undang RI Nomor 20 Tahun 2003, Tenaga Pendidik adalah tenaga kependidikan yang berkualifikasi sebagai guru, dosen, konselor, pamong belajar, widyaiswara, tutor, instruktur, fasilitator dan sebutan lain yang sesuai dengan kekhususannya, serta berpartisipasi dalam penyelenggaraan pendidikan.

Sedangkan pengertian tenaga pendidik yang dijelaskan dalam Undang-undang No. 20 Tahun 2003 Pasal 39 ayat 2 menyatakan bahwa "Pendidik merupakan tenaga profesional yang bertugas merencanakan dan melaksanakan proses pembelajaran, menilai hasil pembelajaran, melakukan pembimbingan dan pelatihan, serta melakukan penelitian dan pengabdian kepada masyarakat, terutama bagi pendidik pada Perguruan Tinggi. Tenaga kependidikan adalah anggota masyarakat yang mengabdikan diri dan diangkat untuk menunjang penyelenggaraan pendidikan." Adapun standar pendidik nasional atau syarat-syarat bagi guru seperti yang telah dijelaskan dalam Peraturan Pemerintah RI nomor 19 tahun 2005 bahwa guru/pendidik harus memiliki kualifikasi akademik dan kompetensi sebagai agen pembelajaran, sehat jasmani dan rohani, serta memiliki kemampuan untuk mewujudkan tujuan pendidikan nasional.

\section{METODE}

Dalam penelitian ini peneliti menggunakan desain penelitian kualitatif deskriptif. Penelitian kualitatif, yaitu metode penelitian yang digunakan untuk meneliti pada kondisi obyek yang alamiah, dimana peneliti adalah sebagai instrumen kunci, teknik pengumpulan data dilakukan secara triangulasi (gabungan), analisa data bersifat induktif/kualitatif, dan hasil penelitian kualitatif lebih menekankan makna daripada generalisasi (Sugiyono,2013). Subjek dalam penelitian ini adalah Kepala Sekolah.

Objek dalam penelitian ini adalah proses rekrutmen tenaga pendidik SDN 1 Sinduadi. Jenis data yang digunakan dalam penelitian ini adalah data kualitatif. Sumber data primer yang diperoleh dari hasil wawancaradengan narasumber dan sumber data 
sekunder berupa visi misi dan tujuan SDN 1 Sinduadi. Penelitian ini menggunakan teknik pengumpulan data dengan wawancara semi terstruktur. Pemilihan informan ini menggunakan teknik Purposive Sampling. Purposive sampling yaitu teknik pengambilan sampel sumber data dengan pertimbangan tertentu (Sugiyono, 2012, pp.218-219). Narasumber yang dipilih yaitu: M. Thoharuddin merupakan kepala sekolah.

\section{a. Dasar Rekrutmen Tenaga Pendidik SDN Sinduadi 1}

Mengacu pendapat Gomes (2003: 105) mengatakan bahwa rekrutmen dilaksanakan dalam suatu organisasi karena kemungkinan adanya lowongan. Berdasarkan hasil wawancara terhadap kepala SDN Sinduadi 1 yaitu Bapak M. Thoharuddin sebagai berikut:

"Sebelum rekrutmen dilaksanakan maka pihak SDN Sinduadi 1 tentu saja menyusun perencanaan, hal yang dilakukan adalah analisis pekerjaan dan analisis jabatan. Kedua analisis ini dilakukan untuk mendapatkan data-data mengenai formasi apa yang kosong, berapa pegawai yang dibutuhkan, dan untuk menentukan persyaratan minimum yang perlu dimiliki oleh calon pegawai. Rekrutmen tenaga pendidik di SDN Sinduadi 1 akan dilaksanakan ketika ada kekurangan dan kekosongan tenaga pendidik".

\section{b. Strategi Rekrutmen Tenaga Pendidik SDN Sinduadi 1}

Strategi menjadi bagian pokok dalam membuat suatu perencanaan yang matang. Sebelum melakukan rekrutmen selalu ada perencanaan sebagai tahap awal yaitu menganalisis kebutuhan, analisis dilakukan supaya sekolah mengetahui berapa jumlah kekurangan guru, pada mata pelajaran apa, dan bagaimana proses rekrutmennya. Strategi yang dibutuhkan seperti sumber, teknik, dan metode rekrutmen. Mengacu pada pendapat Hasibuan (2008), Sumber penarikan calon karyawan bisa berasal dari internal dan eksternal perusahaan. Menurut Priansa (2004), teknik rekrutmen ada dua yaitu teknik desentralisasi dan sentralisasi. Sedangkan metode rekrtutmen menurut Priansa (2004) yaitu metode terbuka dan tertutup. Seperti yang diungkapkan Kepala Sekolah SDN Sinduadi 1 bahwa:

"Tahap awal yang dilakukan dalam merencanakan perekrutan tenaga pendidik baru diawali dengan melihat kebutuhan yang diperlukan oleh sekolah, diantaranya menganalisis jabatan apa yang kososng, jumlah posisi yang kosong, peningkatan jumlah siswa, mutasi pegawai, sakit atau meninggal dunia, kemudian menentukan spesifikasi jurusan, dan menentukan persyaratan yang harus dipenuhi pelamar. Tahap kedua, sekolah menginformasikan adanya lowongan tenaga pendidik secara internal. Tahap ketiga, melakukan seleksi berkas calon guru. Tahap keempat, memanggil calon guru yang lolos seleksi berkas untuk wawancara. Tahap kelima, keputusan hasil calon guru baru.

Selain pernyataan di atas tentunya masih ada strategi lainnya yang perlu diperhatikan dalam perencanaan rekrutmen yaitu sumber, teknik, dan metode reckrutmen. Berdasarkan hasil wawancara dengan kepala sekolah, sumber rekrutmen berasal dari luar (eksternal) sekolah dan teknik rekrutmen yaitu desentralisasi karena tenaga pendidik yang dibutuhkan terbatas/ sedikit. Sedangkan untuk metode rekrutmen yaitu menggunakan metode tertutup dengan mengumumkan jika membutuhkan tenaga pendidik baru melalui mulut ke mulut kepada internal sekolah saja.

c. Persiapan Rekrutmen Tenaga Pendidik SDN Sinduadi 1

Mengacu pada pendapat Hasibuan (2008), persiapan rekrutmen terdiri dari: pembentukan panitia rekrutmen guru baru, pengkajian berbagai undang-undang 
atau peraturan pemerintah, peraturan yayasan yang berkenaan dengan peraturan penerimaan guru, walaupun akhir-akhir ini telah diberlakukan otonomi daerah, penetapan persyaratan-persyaratan untuk melamar menjadi guru baru, penetapan prosedur pendaftaran guru baru, penetapan jadwal rekrutmen guru baru, penyiapan fasilitas yang diperlukan dalam proses rekrutmen guru baru, seperti media pengumuman penerimaan guru baru, format rekapitulasi pelamar, dan format rekapitulasi pelamar yang diterima, penyiapan ruang atau tempat memasukan lamaran guru baru, penyiapan bahan ujian seleksi, pedoman pemeriksaan hasil ujian dan tempat ujian.

Berdasarkan hasil wawancara dengan kepala SDN Sinduadi 1 dalam persiapan pelaksanaan rekrutmen tenaga pendidik pihak Sekolah tidak melakukan pembentukan panitia rekrutmen sebagaimana mestinya. Hal ini dikarenakan tidak ada biaya untuk melakukan itu semua, terlebih gaji sebagai guru honorer yang diperlukan tidak seberapa sehingga jika kekurangan guru hanya pemberitahuan internal saja, tidak melakukan iklan dan lainnya.

Hal tersebut menandakan bahwa pihak sekolah belum melakukan persiapan rekrutmen sebagai mana mestinya.

\section{d. Prosedur Rekrutmen Tenaga Pendidik SDN Sinduadi 1}

Kepala sekolah mengatakan bahwa tata cara dan prosedur penerimaan tenaga pendidik di SDN Sinduadi 1 adalah sebagai berikut: Pertama, pengajuan permohonan lamaran pekerjaan dengan kelengkapan administrasi/lampiranlampiran yang diperlukan seperti surat lamaran, daftar riwayat hidup, pas foto, foto copy kartu identitas, foto copy ijazah dan transkrip nilai, foto copy sertifikat-sertifikat yang dimiliki, foto copy referensi pengalaman kerja. Kedua, seleksi berkas. Ketiga, pemanggilan pelamar yang lolos seleksi berkas untuk wawancara. Keempat, keputusan hasil pelamar yang diterima.

\section{e. Proses Pelaksanaan Rekrutmen}

Tahapan proses rekrutmen yang pertama adalah membuka lowongan yang dilakukan dengan mempublikasikan hanya memberitahukan kepada staf guru yang ada di SDN Sinduadi 1. Bapak Kepala SDN Sinduadi 1 tidak mempublikasikan lewat koran ataupun media lainnya dikarenakan keterbatasan biaya.

Setelah pelamar mengajukan lamaran kemudian kepala sekolah menampung berkas lamaran dan melakukan penyeleksian berkas. Untuk kriteria yang lolos administrasi, Bapak M. Thoharuddin hanya melihat dari biodata pelamar, pengalaman, dan melihat fotonya. Menurut Bapak M. Thoharuddin, Kualifikasi atau syarat-syarat yang harus dipenuhi oleh calon tenaga pendidik yaitu sesuai standar yang ditentukan pemerintah, diantaranya: 1) Pendidikan minimal $S 1$ sesuai bidangnya, 2) umur maksimal 28 tahun, 3) pria/wanita, 4) mampu mengoperasikan komputer diprioritaskan. Seleksi tenaga kependidikan mengacu kepada dua hal pokok yaitu kemampuan akademik yang bertumpu pada penampilan intelektual dan penguasaan disiplin akademik, serta kepribadian

Setelah selesai memilih pelamar yang lolos kemudian kepala sekolah memanggil pelamar dengan cara menghubungi pelamar yang bersangkutan via telepon untuk datang ke sekolah untuk melakukan wawancara.

Disini kepala sekolah tidak melakukan tes pengetahuan, tes psikologi, dan micro teaching. Hal tersebut dikarenakan keterbatasan biaya dan melihat gaji yang akan ditawarkan tidak seberapa. Sehingga kepala sekolah hanya melakukan wawancara saja untuk mengetahui penampilan dan kepribadian pelamar. Bapak M. Thoharuddin berpendapat bahwa seorang guru yang memiliki penampilan dan kepribadian yang baik, insya allah dapat mendidik anak dengan baik pula.

Adapun kendala-kendala yang dihadapi ketika pihak sekolah melakukan rekrutmen yaitu kebanyakan berkas lamaran yang masuk belum sesuai dengan 
kualifikasi yang diharapkan, keterlambatan berkas yang masuk ke sekolah.

Maksudnya guru yang sudah didapatkan kemudian berkas baru masuk.

\section{SIMPULAN}

Dari hasil penelitian menunjukkan bahwa secara umum manajemen tenaga pendidik (rekrutmen dan seleksi) di SDN Sinduadi 1 masih kurang terkoordinasi.

Dalam perencanaan rekrutmen, sekolah sudah melakukan analisis jabatan yang dibutuhkan, menentukan strategi rekrutmen seperti pengumuman lowongan guru baru dalam lingkup internal dan menggunkan sumber, teknik, dan metode rekrutmen yang sesuai dengan peraturan. Kepala sekolah juga sudah menentukan prosedur rekrutmen.

Pelaksanaan rekrutmen, sekolah ini tidak pernah melakukan pengumuman di media massa baik cetak maupun elektronik mengenai kebutuhan tenaga pendidik baru. Kepala sekolah hanya mengumumkan dilingkup internal kepada staff guru, penyeleksian dilakukan oleh kepala sekolah dengan cara seleksi berkas kemudian dilanjutkan dengan wawancara. Setelah wawancara kemudian kepala sekolah memutuskan calon guru yang diterima. Dalam proses seleksi, sekolah tidak pernah melakukan tes-tes lain selain tes wawancara secara mendalam dengan kepala sekolah langsung dan wakil kepala sekolah. Tidak ada tes kesehatan juga tidak ada tes secara praktik dalam mengajar seperti masa percobaan.

Untuk hasil tenaga pendidik yang diterima di SDN Sinduadi 1 sudah sesuai dengan kualifikasi yang diharapkan. Adapun kendala-kendala yang dihadapi ketika pihak sekolah melakukan rekrutmen yaitu kebanyakan berkas lamaran yang masuk belum sesuai dengan kualifikasi yang diharapkan dan keterlambatan berkas yang masuk ke sekolah.

\section{DAFTAR PUSTAKA}

Gomes, F. C. (2003). Manjemen Sumber Daya Manusia. Yogyakarta : C.V Andi Offset Hasibuan, M.S.P. (2008). Manajemen Sumber Daya Manusia. Jakarta: PT Inti Indrayu Press

Hasibuan, M.S.P. (2012). Manajemen Sumber Daya Manusia. Jakarta: PT Bumi. Aksara

Jones, G. R. (2004). Essentials of Contemporary Management, (New York: McGrawHill

Kasmir. (2012). Manajemen Sumber Daya Manusia Teori dan Praktik (jakarta : Rajawali Pers

Priansa, D.J . (2014.) Perencanaan dan Pengembangan SDM. Bandung : Alfabeta

Pynes, Joan E. (2002). Human Resource Management for Public and Nonprofit Organizations. Second edition. San Francisco: Jossey-Bass

Undang-Undang No.20 Tahun 2003 tentang Sistem Pendidikan Nasional. Jakarta: Depdiknas

Undang-Undang RI Nomor 14 Tahun 2005 \& Peraturan Pemerintah RI Nomor 74 Tahun 2008 Tentang Guru Dan Dosen, (Bandung: Citra Umbara, 2009) 